\title{
A IMPORTÂNCIA DA AVALIAÇÃO FORMATIVA EM FEIRAS DE CIÊNCIAS
}

\author{
LA IMPORTANCIA DE LA EVALUACIÓN FORMATIVA EN FERIAS DE CIENCIAS
}

THE IMPORTANCE OF FORMATIVE EVALUATION IN SCIENCE FAIRS

\author{
Soraia da Silva VICTORIO ${ }^{1}$ \\ Marcos Cesar Rodrigues de MIRANDA ${ }^{2}$ \\ Rosebelly Nunes MARQUES ${ }^{3}$
}

RESUMO: A Avaliação Formativa $[\mathrm{AF}]$ é decorrente da pedagogia formativa e busca abrir novos caminhos para a educação, sendo uma concepção de ensino a qual considera que o aprender é um processo longo onde o aluno reestrutura seu conhecimento a partir das atividades que realiza. As Feiras de Ciências [FC] podem ser aliadas da AF nas escolas por serem consideradas atividades de educação não formal, com a finalidade de promover $o$ desenvolvimento da cultura científica. O presente estudo procurou analisar os efeitos da $\mathrm{AF}$ em uma FC com alunos do Ensino Fundamental nos anos finais. Partiu-se de uma análise documental sobre o percurso dos alunos durante o projeto intitulado como FC. A AF fica evidenciada em várias etapas do processo. O projeto pesquisado foi formativo, pois ajudou os alunos a aprenderem a se desenvolver, participando das regulações das aprendizagens e do desenvolvimento no sentido de um projeto educativo dentro da escola.

PALAVRAS-CHAVE: Divulgação científica. Ensino fundamental. Mostra de ciências. Trabalho em equipe. Autonomia do aluno.

RESUMEN: La Evaluación Formativa [EF] es producto de la pedagogía formativa y busca abrir nuevos horizontes para la educación, siendo una concepción de enseñanza que considera aprender como un proceso largo en el cual el alumno reestructura su conocimiento a partir de las actividades que realiza. Las Ferias de Ciencias [FC] pueden ser una aliada en la EF de las escuelas por ser consideradas actividades de educación en el ámbito formal, con la finalidad de promover el desarrollo de la cultura científica. El presente estudio procuró analizar los efectos de la EF en una FC con alumnos de los últimos años de la Enseñanza Primaria. Se partió de un análisis documental sobre el recorrido de los alumnos durante el proyecto intitulado como FC. La EF Queda en evidencia en varias etapas del proceso. El proyecto pesquisado fue formativo, pues ayudó a los alumnos a aprender a desarrollarse, participando de las regulaciones de los aprendizajes y del desarrollo en el sentido de un proyecto educativo dentro de la Escuela.

\footnotetext{
${ }^{1}$ Associação de Educação e Cultura São Paulo (ESP), Holambra - SP - Brasil. Professora de Ciências. Mestre em Biologia Vegetal. ORCID: https://orcid.org/0000-0003-3778-0795. E-mail: soraia.victorio@ gmail.com

2 Programa de Educação Continuada em Economia e Gestão de Empresas (PECEGE), Piracicaba - SP - Brasil. Professor Associado. Mestre em Ensino em Química. ORCID: http://orcid.org/0000-0002-4442-9971. E-mail: marcos199697@gmail.com

3 Universidade de São Paulo (USP), Piracicaba - SP - Brasil. Docente do Departamento de Economia, Administração e Sociologia. ORCID: https://orcid.org/0000-0002-8726-3211. E-mail: rosebelly.esalq@usp.br
} 
PALABRAS CLAVE: Divulgación científica. Enseñanza fundamental. Show de ciencias. Trabajo en equipo. Autonomía estudiantil.

ABSTRACT: The Formative Assessment (FA) is a result of formative pedagogy and intends to open new paths for education, being a teaching conception, which considers that learning is a long process where the student restructures their knowledge from the activities they perform. Science Fairs (SF) can be an ally in FA in schools because they are considered non-formal educational activities with the purpose of promoting development of scientific culture. The present study aimed to analyze the effects of FA on a SF with elementary school students in the final years. It started from a documented analysis about the students' path during the project entitled as SF. The FA is evident through many steps of the process. The researched project was formative as it helped students learn how to develop themselves by participating in the learning regulations and development towards an educational project within the school.

KEYWORDS: Scientific dissemination. Elementary school. Science fair. Team work. Student autonomy.

\section{Introdução}

A educação básica é formada pela Educação Infantil (até os cinco anos), Ensino Fundamental (dos seis aos quatorze anos) e Ensino Médio (dos quinze aos dezessete anos). O ensino fundamental tem duração de nove anos, sendo os primeiros cinco anos (Ensino Fundamental I - EFI) ministrados, em sua maioria, por professoras polivalentes, que interagem ao longo de todo um ano letivo com um mesmo grupo de alunos. Nos anos finais do Ensino Fundamental (Ensino Fundamental II - EFII) os alunos vivenciam novas experiências no cotidiano escolar como, o aumento no número de docentes (agora especialistas) na grade curricular de ensino, com níveis de exigências e estilos de organização social e didática de aulas totalmente distintos; demandando maiores responsabilidades aos alunos, ampliando a complexidade com que os conteúdos são abordados, aproximando-se assim, da estrutura escolar empregada no Ensino Médio.

Muitas são as críticas relacionadas a fragmentação das disciplinas e a interação dos alunos com os novos professores na passagem do $5^{\circ}$ ano $[\mathrm{EFI}]$ para o $6^{\circ}[\mathrm{EFII}]$ ano do Ensino Fundamental. Muitos docentes preocupam-se mais em seguir o cronograma e alegam que os alunos são imaturos, indisciplinados e sem base, e enfatizam a total responsabilidade dos alunos na organização dos estudos e das lições. Outros ignoram a revisão dos conteúdos trabalhados nos anos iniciais, desconsideram o conhecimento dos alunos sobre os conteúdos propostos, minimizam sua bagagem cultural, seus hábitos escolares e suas atitudes (DIAS-DA-SILVA, 1997). Como cada docente acompanha o aluno apenas na disciplina que ministra, as ações 
dirigidas aos alunos acabam por serem pouco planejadas. Como resultado, a estrutura de funcionamento da escola para as séries finais do Ensino Fundamental acaba por não possibilitar articulações necessárias no planejamento e na execução de formas eficazes de ensino.

Além disso, prevalece o conceito de que o ensino tradicional está interessado nos percentuais de aprovação e reprovação e, tendo em vista esta questão, as escolas acabam por adotar uma pedagogia de exames, perdendo a característica de pedagogia de ensino e aprendizagem (GREGO, 2013). Pais ou responsáveis, escola, profissionais da educação, docentes e discentes, todos têm suas atenções centradas na promoção, ou não, do estudante de uma série de escolaridade para outra (LUCKESI, 2011). A apropriação ou não-apropriação do aprendizado pelos alunos é consequência das exigências adotadas pelos docentes ou outras avaliações externas que aderem ao ensino estruturado (PERRENOUD, 1999).

A avaliação da aprendizagem tem por objetivo auxiliar o educando no seu crescimento, na sua integração consigo mesmo, ajudando-o na apropriação de conteúdos significativos. A avaliação apresenta-se como meio constante de fornecer suporte ao educando no seu processo de assimilação de conteúdos e construção de si mesmo como sujeito existencial e cidadão (LUCKESI, 2011).

De um ciclo de estudos ao seguinte, até mesmo entre os anos escolares a função da avaliação tradicional é de certificar aquisições. Uma certificação fornece poucos detalhes dos saberes das competências adquiridas e do nível de domínio atingido em cada campo abrangido pelo aluno. O que certifica ao professor, que recebe os alunos oriundos do nível ou do ciclo anterior, que ele poderá trabalhar como usualmente (PERRENOUD, 1999). A avaliação formativa gera aos professores informações mais assertivas e qualitativas sobre os processos de ensino e aprendizagem dos alunos.

A avaliação formativa é decorrente da pedagogia formativa e busca abrir novos caminhos para a educação, sendo uma concepção de ensino a qual considera que o aprender é um processo longo em que o aluno reestrutura seu conhecimento a partir das atividades que realiza. O termo avaliação formativa, introduzido em 1967 por M. Scriven, se refere aos procedimentos utilizados pelos professores a fim de adaptarem o seu processo didático aos progressos e necessidades da aprendizagem do aluno observado (GARUTTI, 2010). Sendo assim, a avaliação formativa abrange todas as práticas desenvolvidas pelos professores e seus alunos, com a finalidade de ceder referências a serem usadas como efeito retroativo para assim reestruturar o trabalho pedagógico. Essa devolutiva é o principal elemento na avaliação formativa, refere-se à construção do conhecimento, em decorrência do empenho e do êxito no trabalho desenvolvido pelo próprio aluno (VILLAS BOAS, 2008). O objetivo do trabalho 
pedagógico é assessorar a transição das devolutivas para o auto monitoramento, desenvolvendo assim a autonomia intelectual do aluno.

As Feiras de ciências, também chamadas de Mostra de Ciências podem ser uma aliada na avaliação formativa nas escolas. Elas são atividades de educação não formal, que podem ocorrer tanto em espaços formais como não formais, com a finalidade de promover o desenvolvimento da cultura científica. São eventos sociais, científicos e culturais realizados nas escolas ou na comunidade com a intenção de, durante a apresentação dos estudantes, oportunizar um diálogo com os visitantes, constituindo-se na oportunidade de discussão sobre os conhecimentos, metodologias de pesquisa e criatividade dos alunos em todos os aspectos referentes à exibição de trabalhos (SANTOS, 2012).

Com início no país na década de 60 , as feiras foram produtos oriundos dos centros de ciências, que tinham como objetivo revisar todo conteúdo estrangeiro e capacitar as escolas do país sobre o ensino de ciências, possibilitando inúmeras atividades voltadas para a prática no ensino, entre elas as Feiras e os Clubes de Ciências, as primeiras ocorreram em São Paulo nas instalações da Galeria Prestes Maia (BRASIL, 2006). Desde seu início ela tem como objetivo divulgar o conhecimento científico, fazendo com que os alunos dialoguem com o público assuntos que ele dedicou interesse, tempo, curiosidade, para que finalmente desenvolvesse a desenvoltura para expressar sua visão desse conhecimento. Dessa forma, o aluno passa a enxergar a ciência com seu olhar, tornando o conhecimento dinâmico e possibilitando que seus ouvintes também tenham a oportunidade de criar sua própria visão da ciência, ou seja, divulgar e popularizar a ciência.

Neste contexto, o presente estudo procurou analisar os efeitos da avaliação formativa em uma feira de ciências com alunos do Ensino Fundamental anos finais.

\section{Metodologia}

A pesquisa se enquadra como exploratória, tendo natureza quali-quantitativa, com coleta de dados por meio de pesquisa documental e com análise de conteúdo.

A análise documental, segundo BARDIN (1977) é um conjunto de operações que visa representar o conteúdo de um documento sob uma forma diferente da original, a fim de facilitar posteriormente, a sua consulta e referenciação. Tem por objetivo dar forma conveniente e representar de outro modo essa informação, por intermédio de procedimentos de transformação. O propósito a atingir é: o armazenamento sob uma forma variável; e a facilitação do acesso ao observador, de tal forma que este obtenha o máximo de informação (aspecto quantitativo) com 
o máximo de pertinência (aspecto qualitativo). A análise de conteúdo é apresentada como um método de efetuar a exploração total e objetiva dos documentos.

Partiu-se de uma análise documental sobre o percurso dos alunos do Ensino Fundamental Anos Finais durante o projeto intitulado como Feira de Ciências ano 2017. Os documentos analisados foram:

- Cronograma da Feira: foi analisado em quais datas ocorreram os percursos que os alunos passaram durante o processo.

- Tabela de Formação dos grupos: esclarece a quantidade de alunos participantes na feira e como os grupos foram formados.

- Tabela de temas e orientadores: demonstra quais os temas escolhidos e a quantidade de professores que fizeram o processo de orientação.

- $\quad$ Ficha de avaliação do trabalho escrito: descreve a forma e quais os critérios de avaliação utilizados no processo.

- $\quad$ Ficha de avaliação de apresentação de trabalho em sala e apresentação no evento: descreve a forma e quais critérios foram utilizados para a apresentação em sala e no dia do evento, sendo esses critérios diferentes dos que foram utilizados no trabalho escrito.

- $\quad$ Tabela de notas dos grupos nas avaliações: essas tabelas foram utilizadas para parametrizar os resultados obtidos pelos alunos em cada etapa do processo.

- Tabelas de bônus dos alunos: essa tabela representa um resultado final sobre o quanto a avaliação da feira pode contribuir com cada grupo para compor as notas do $2^{\circ}$ e $3^{\circ}$ trimestre do ano letivo.

A partir da análise e levantamento desses dados foi possível criar um panorama do objeto de estudo que será discutido posteriormente.

\section{Resultados e Discussão}

A escola desse estudo faz parte da rede particular de ensino em Holambra, São Paulo. Teve início em 1949, em uma escola rural que passou a atender filhos de imigrantes holandeses que chegavam no país após a $2^{\mathrm{a}}$ Guerra Mundial. A oficialização da escola se deu em dezembro de 1951, sendo a Cooperativa de imigrantes como mantenedora da escola, atendendo somente crianças do ensino primário, hoje Fundamental I. Com o passar dos anos, houve a implantação do Ensino Fundamental II, o desligamento da Cooperativa, a formação de uma Associação e de 
uma Comissão para trabalhar junto à Comissão de Pais na implantação do Ensino Médio e posterior implantação do Sistema Didático.

Hoje, a escola atende não somente a comunidade local, mas também vários municípios do entorno. O prédio conta com distintas salas de aula, laboratório de ciências, laboratório de robótica, sala de música, ateliê de arte, salas diversas (direção, coordenação, secretaria, enfermaria, professores), biblioteca, refeitório e duas quadras poliesportivas. A escola atende na Educação Infantil [EI] 51 alunos, no Ensino Fundamental I [EFI] 148 alunos, no Ensino Fundamental II [EFII] 130 alunos, no Ensino Médio [EM] 86 alunos e High School [HS] 10 alunos. A EI e a EFI contam com uma coordenadora pedagógica, nove professores e três monitoras para o EI, doze professores e uma monitora para o EFI. O EFII conta com um coordenador pedagógico e quatorze professores. O EM conta com um coordenador pedagógico, um orientador educacional e dezessete professores. A escola conta ainda com uma bibliotecária, uma orientadora educacional, equipe administrativa, equipe de informática, auxiliar de manutenção, equipe de limpeza, equipe de cozinha e serviço terceirizado de refeitório.

A feira de ciências teve início em 2006 e foi sofrendo modificações ao longo dos anos. Saiu de uma amostra de experimentos com temas dividido por salas e dirigiu-se para o modelo atual.

No ano de 2017 a feira de ciências teve um total de 129 alunos participantes, compondo 26 grupos de trabalhos com orientação de 10 professores. Durante o mês de fevereiro os alunos deveriam formar equipes de 4 a 5 alunos, a depender a sala, e definir o tema do trabalho. $\mathrm{O}$ prazo final para a definição das equipes e escolha inicial dos temas foi no final do mês de fevereiro. A quantidade de equipes por sala foi estabelecida pelos responsáveis pela organização e fixado de acordo com o número de alunos por sala. $\mathrm{O} 6^{\circ}$ ano $\mathrm{A}$ e o $6^{\circ}$ ano $\mathrm{B}$ foram divididos em 2 equipes de 5 alunos e 2 equipes de 4 alunos, totalizando 18 alunos cada sala. $\mathrm{O}$ $7^{\mathrm{o}}$ ano apresentava 5 equipes de 5 alunos cada, totalizando 25 alunos. O $8^{\circ}$ ano apresentava 3 equipes de 5 e 1 equipe de 4 alunos, totalizando 19 alunos. O $9^{\circ}$ ano A apresentava 24 alunos sendo dividido em 4 equipes, 3 equipes de 5 e 1 equipe de 4 alunos. $\mathrm{O} 9^{\circ}$ ano $\mathrm{B}$ apresentava 5 equipes de 5 alunos cada, totalizando 25 alunos. A equipes seguiram um cronograma de atividades (Figura 1) indicando o mês, o dia e o prazo de entrega da atividade a ser trabalhada. 
Figura 1 - Cronograma Feira

\begin{tabular}{|c|c|}
\hline FEVEREIRO & -Definição de grupos e temas dos trabalhos \\
\hline & $\begin{array}{l}\text {-Avaliação dos temas (segurança) } \\
\text { - Troca de temas } \\
\text {-Avaliação dos novos temas } \\
\text {-Fechamento dos temas }\end{array}$ \\
\hline MA & $\begin{array}{l}\text {-Verificação - Diário de Bordo e Trabalho } \\
\text { - Orientação nas refências } \\
\text {-Devolução das orientaçães }\end{array}$ \\
\hline JUNF & $\begin{array}{l}\text {-Devolução dos textos para possíveis correçães } \\
\left.\text { - Avaliação Trabalho escrito (1 } 1^{a} \text { nota - bônus } 1\right)\end{array}$ \\
\hline $\mathrm{AG}$ & -Apresentação em sala ( $2^{\mathrm{a}}$ nota - bônus 2 ) \\
\hline SETEMBRO & •Apresentação na Feira de Ciências (3a nota - bônus 2) \\
\hline
\end{tabular}

Fonte: Elaboração própria.

A escolha dos temas dos trabalhos foi feita livremente pelos alunos, dentro do prazo de 5 dias do mês de março, com posterior análise dos professores avaliadores com relação à relevância e o grau de periculosidade. Sendo assim, foram excluídos temas envolvendo vídeos demonstrativos de experimentos sem conteúdo científico e, também, aqueles que necessitassem de um acompanhamento individual de um adulto, devido ao risco provocado pelo experimento. Os trabalhos que apresentaram tais características tiveram mais 5 dias para a troca e readequação. Após isso, os novos temas foram reavaliados. O fechamento geral dos temas ocorreu no final do mês de março com a impossibilidade de troca. Cabe destacar que os verdadeiros projetos são construídos em direção a uma autoridade negociada na construção substancial da autonomia dos alunos, resultante de uma real responsabilidade entregue a eles (PERRENOUD, 1999).

A escolha dos orientadores foi definida através do tema gerador de cada trabalho e distribuídos assim para 10 professores das frentes das respectivas disciplinas relacionadas aos temas propostos. Cada orientador tinha a responsabilidade de conduzir os alunos na melhoria do desenvolvimento do trabalho escrito, se houve ou não avanços, que aspectos poderiam ser melhorados passando assim por possíveis correções propostas em datas anteriores a avaliação, indicando os possíveis caminhos para a melhoria da estrutura do trabalho. Durante o mês de maio as equipes reuniram-se com seus respectivos orientadores para o desenvolvimento do trabalho escrito e do diário de bordo, o qual descreveu todos os encontros dos integrantes do 
grupo e o passo a passo do que foi realizado para o progresso da pesquisa. Os orientadores auxiliaram na melhoria da escrita do trabalho escrito com a busca e indicação de textos complementares. Segundo PERRENOUD (1999), na pedagogia da expressão escrita, em uma avaliação formativa, a produção de textos deve inserir-se em um procedimento didático coerente, com hipóteses precisas sobre a maneira como se constroem competências e sobre a natureza dos prováveis erros dos alunos.

No mês de junho as equipes fizeram a devolução dos textos aos respectivos orientadores e estes os analisaram e relataram as últimas correções a serem feitas. O prazo final para a entrega do trabalho escrito foi no final desse mês, sendo essa a primeira avaliação e a primeira nota bônus que serviria para o segundo trimestre. Villas Boas (2008) destaca que esse retorno de resposta é o principal elemento da avaliação formativa, atende professor e aluno, o primeiro delibera ações sobre iniciativa, diagnose e recuperação, já o segundo o usa para acompanhar suas competências, habilidades e percepções no seu desempenho com o propósito de atingir o reconhecido sucesso, como também modificar ou aprimorar resultados insatisfatórios.

O trabalho escrito foi avaliado pelos professores responsáveis pela organização da feira e seguiu os critérios como: de organização e estrutura do texto (modelo a ser seguido pelos grupos), de embasamento teórico (textos e sites confiáveis), de clareza, da confecção do diário de bordo (detalhando os encontros e o que foi produzido pelo grupo e participação dos integrantes) e, por fim, recebeu a nota do professor responsável pelo projeto (Figura 2). Essa última nota era dada pelo professor orientador, que supervisionou todas as atividades desenvolvidas desde o início com os seus alunos, com o intuito de verificar se as informações e feedbacks foram usadas para a reorganização do trabalho pedagógico, ou seja, se os alunos seguiram as orientações do professor. A qualidade do trabalho é determinada por julgamento qualitativo. Conforme Villas Boas (2008), a avaliação formativa ocorre nas interações do aluno com o professor e com os outros alunos, possibilitando adaptações contínuas enquanto se desenvolve a aprendizagem. 
Figura 2 - Critérios para atribuir nota ao trabalho escrito

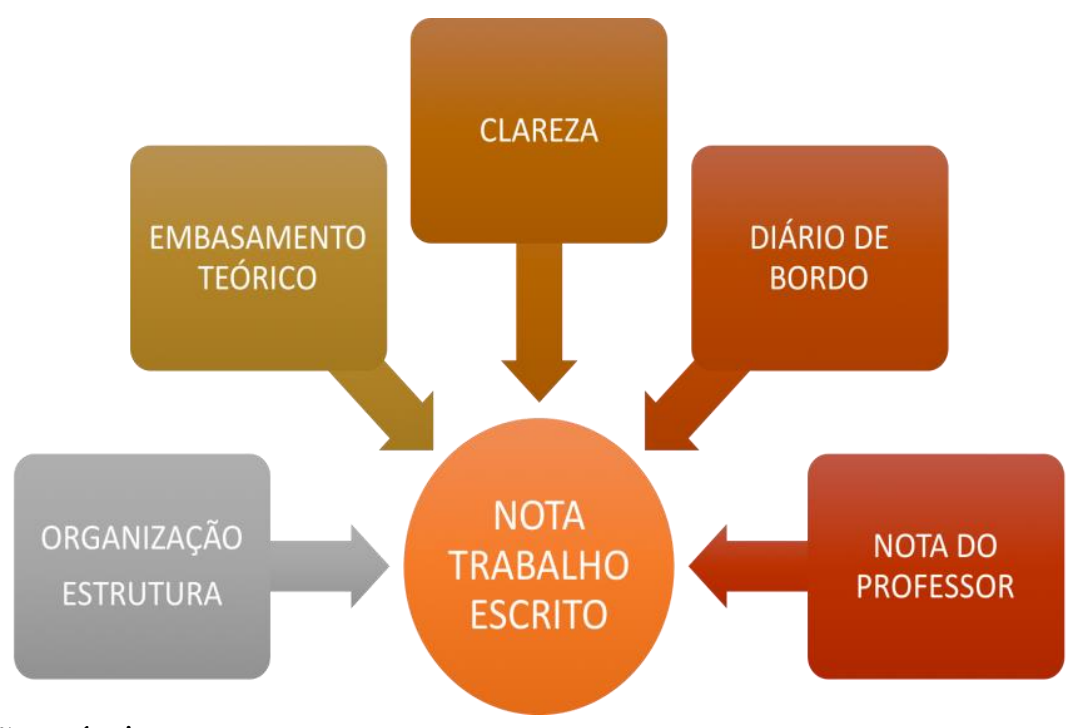

Fonte: Elaboração própria

No segundo semestre, durante o mês de agosto, as equipes apresentaram os trabalhos em sala para os professores responsáveis pela organização da feira e para o restante da turma, gerando assim, uma avaliação e a primeira parte da nota do bônus do terceiro trimestre. Essa apresentação ocorreu dentro do horário de aula, com tempo limite de 10 minutos. As falas deveriam ser divididas entre todos os integrantes da equipe, seguindo critérios de organização e utilizando-se de todos os recursos que seriam necessários e utilizados na apresentação final no dia da feira. Os critérios avaliados foram: a organização, a apresentação oral, o domínio do tema, a interação do grupo e, também, a nota recebida pela equipe no trabalho escrito (Figura 3). Nesse processo destaca-se a avaliação por colegas e a auto avaliação. Segundo Villas Boas (2008), a avaliação por colegas do mesmo grupo é um componente importante no processo avaliativo e pode ser o primeiro passo para a auto avaliação. Esse tipo de avaliação permite a participação dos alunos e aumenta a comunicação entre eles e o professor, sobre sua aprendizagem. 
Figura 3 - Critérios avaliados nas apresentações em sala e na feira

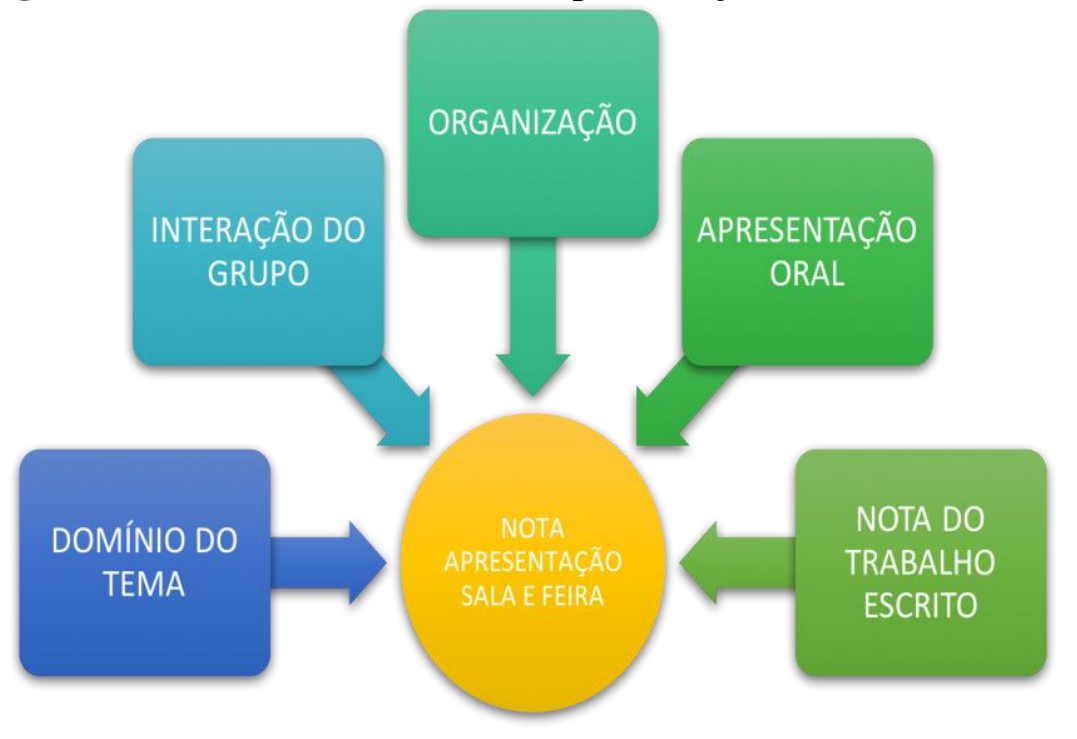

Fonte: Elaboração própria

A última apresentação com as adequações sugeridas na etapa anterior ocorreu no início de setembro, sendo realizada uma segunda avaliação que completaria a nota de bônus para o terceiro trimestre. Ela ocorreu na quadra poliesportiva da escola seguindo o horário das 8:00 às 12:30. O local foi previamente apresentado às equipes para que se organizassem nesse limite de espaço. Foram disponibilizadas duas mesas para cada equipe, além de tomadas para aqueles que utilizaram aparelhos eletrônicos. Diversos recursos foram utilizados nesse dia, como experimentos, banners, jogos, aplicativos. O público da feira foi variado, com a presença de alunos da [EI], do [EFI], do [EM] e familiares de alunos da escola. Para Santos (2012), tais eventos científicos possibilitam diálogos entre visitantes e estudantes, motivando-os, sendo uma oportunidade para os alunos exporem seus conhecimentos científicos, desenvolverem sua criatividade e consequentemente sua autonomia intelectual. Os trabalhos foram novamente apresentados para os professores responsáveis pela organização da feira, os quais seguiram os mesmos critérios avaliados em sala, indicados anteriormente na Figura 3.

Ao final das duas etapas programadas foram geradas três avaliações: trabalho escrito, apresentação em sala e apresentação na feira. Para cada critério analisado foi atribuída uma nota de 1 a 5 pontos, sendo 5 para excelente, 4 para ótimo, 3 para bom, 2 para regular e 1 para fraco. No final fez-se uma média das pontuações dos critérios gerando uma nota, essa nota se transformou em bônus, na primeira etapa essa nota era constituída somente do trabalho escrito, na segunda etapa a nota foi construída a partir das duas apresentações (em sala e no dia da feira), dessa forma os alunos tiveram bônus em dois dos três trimestres do ano letivo. Cada aluno distribuiu os pontos ganhos em atividades desenvolvidas no segundo e terceiro trimestres, 
nas diferentes disciplinas, sendo a nota mínima de 0,5 e a nota máxima 1,0 para cada atividade e matéria. Esse bônus é uma forma de valorizar a participação e o empenho do aluno no desenvolvimento de todas as etapas do trabalho, através de uma avaliação formativa além de considerar diversos aspectos, como pesquisa, escrita, comunicação, trabalho em equipe, fazendo assim uma avaliação global do aluno. Na primeira etapa a média de bônus para os grupos foi de 3,8 , na segunda etapa foi de 4,3.

A Figura 4 faz uma comparação de desempenho na apresentação em sala e na apresentação na feira por grupo de trabalho, em seus respectivos anos. Todas as salas obtiveram um aumento significativo. $\mathrm{O} 6^{\circ}$ ano apresentou em média um aumento de 0,4 pontos, $\mathrm{o} 7^{\circ}$ ano 1,7 pontos, o $8^{\circ}$ ano 1,3 pontos e o $9^{\circ}$ ano 0,8 pontos. Esses resultados demonstram que a simulação da apresentação em sala foi importante para a melhoria dos resultados na apresentação no dia do evento e corroboram com todo o caminho percorrido pela avaliação formativa. Considerando que o arredondamento das notas possibilita a cada aluno da equipe o direito em aumentar, no mínimo, 0,5 pontos em atividades desenvolvidas em sala por matéria, esse aumento faz com que melhore a possibilidade de que outras matérias possam ser incluídas no processo, isso acrescenta 1 matéria a mais no $6^{\circ}$ ano, que teve o menor aumento, a até 4 no $7^{\circ}$ ano, a sala que teve o maior aumento.

Figura 4 - Comparativo de desempenho nas duas apresentações: sala e feira

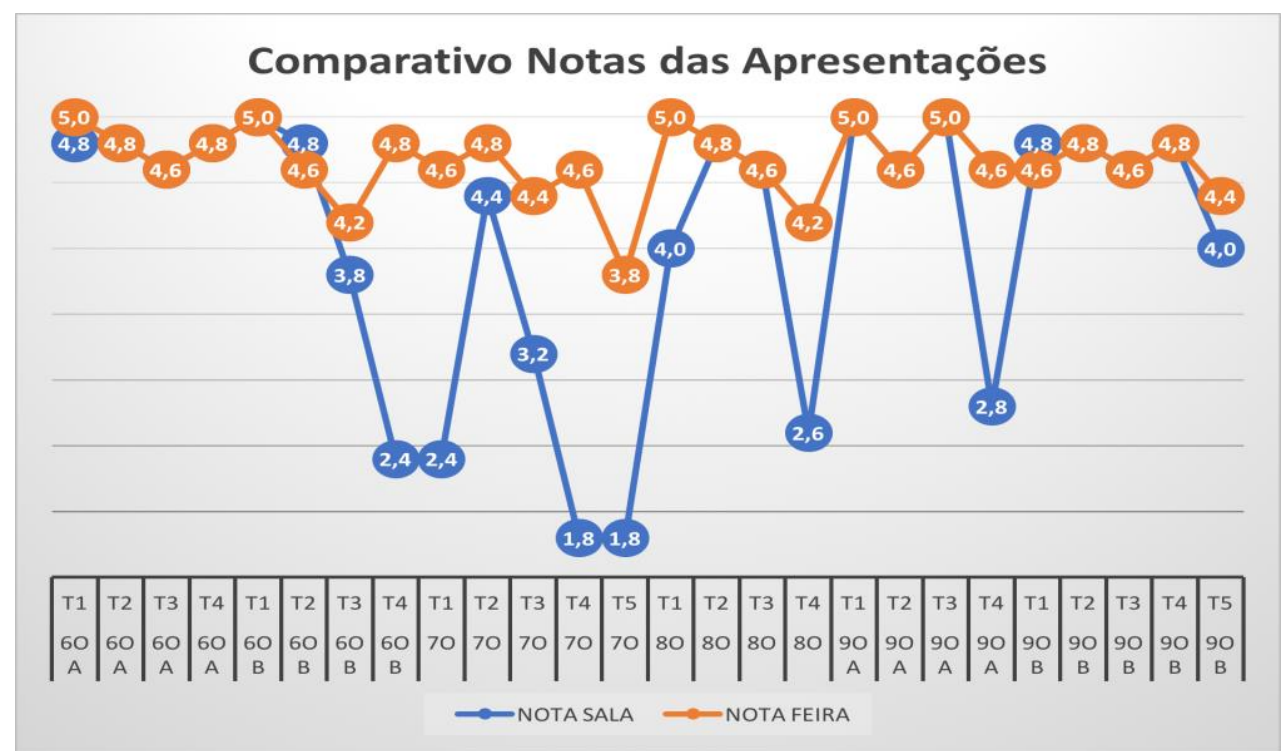

Fonte: Elaboração própria.

A avaliação formativa fica evidenciada em várias partes do processo, a primeira delas ocorre no papel do orientador, o qual através da indicação de materiais para construção do 
trabalho ensina como e onde buscar referências para embasar a escrita, também nas correções que acontecem durante o acompanhamento da escrita, verificando, direcionando um caminho a ser seguido para que o objetivo seja alcançado. Somente depois de todo esse processo, essa estruturação e acompanhamento, o aluno é avaliado de maneira objetiva.

A segunda evidência aparece quando os alunos apresentam em sala, onde eles simulam a apresentação que farão na feira, os professores apontam os pontos positivos e negativos para que eles melhorem seus resultados, ocorre também uma simulação com o público da sala, fazendo com que o aluno vivencie o que acontecerá no dia do evento.

Através da troca desenvolvida entre alunos, professores, comunidade e família, as feiras de ciências permitiram desenvolver e expressar algumas das competências estabelecidas pela Base Nacional Comum Curricular [BNCC] no Ensino Fundamental anos finais. Tal documento define conhecimentos essenciais e fundamentais para a educação básica, estabelecendo habilidades e competências em cada etapa do ensino. Foram abrangidas 8 das 10 competências gerais. Sendo assim a feira de ciências permitiu aos alunos o aumento do conhecimento ao explicarem uma realidade; a exposição de um pensamento científico, crítico e criativo ao investigarem problemas; praticarem a comunicação; desenvolverem a cultura digital utilizandose de tecnologias; entenderem o mundo do trabalho e fazer escolhas alinhadas ao projeto de vida; discorrer sobre suas argumentações; praticar a empatia e a cooperação entre os pares; tomarem decisões que requerem responsabilidade e cidadania.

\section{Considerações finais}

Os resultados dessa pesquisa permitiram revelar os efeitos da avaliação formativa, que foi evidenciada qualitativamente e quantitativamente em cada fase analisada, durante todo o processo de construção da feira, sendo possível de destacar o desempenho dos alunos durante a criação e desenvolvimento dos seus trabalhos em equipe. Cabe destacar as ações facilitadoras como: a troca de informações e de materiais para a elaboração do trabalho escrito, a apresentação das equipes em sala, a avaliação por colegas da mesma equipe e também a do professor avaliador. A observação dos pontos positivos e negativos para a melhora de seus resultados, a vivência das práticas avaliativas realizadas, foram condições necessárias para que ocorresse a transição do feedback para o auto monitoramento, objetivo principal da avaliação formativa, desenvolvendo assim, a autonomia intelectual do aluno. Assim o projeto feira de ciências da escola foi formativo, pois ajudou os alunos a aprenderem formas de se desenvolver, participando das regulações das aprendizagens e do desenvolvimento no sentido de um projeto 
educativo dentro da escola. Espera-se que essa pesquisa auxilie na divulgação sobre a importância da avaliação formativa em feiras de ciências, para que projetos semelhantes possam beneficiar outras instituições de ensino.

\section{REFERÊNCIAS}

BARDIN. L. Analise de conteúdo. 1. ed. Lisboa, Portugal: Editora Edições 70, 1977.

BRASIL. Ministério da Educação. Secretaria de Educação Básica. Programa Nacional de Apoio às Feiras de Ciências da Educação Básica - Fenaceb. Brasília, DF, 2006.

BRASIL. Ministério da Educação. Secretaria da Educação Básica. Base nacional comum curricular [BNCC]. Brasília, DF, 2016. Disponível em:

http://basenacionalcomum.mec.gov.br/\#/site/inicio. Acesso em junho de 2019.

DIAS-DA-SILVA, M. H. G. F. Passagem sem rito: as $5^{\mathrm{a}}$ s séries e seus professores. Campinas, SP, Brasil: Editora Papirus, 1997.

GARUTTI, S. Discutindo a avaliação formativa nas disciplinas de Ciências e Biologia. Revista Uniandrade, v. 11, n. 1, p. 37-52, 2010.

GREGO, S. M. D. A Avaliação Formativa: Ressignificando Concepções e Processos. In: Universidade Estadual Paulista, Pró-Reitoria de Graduação. (Org.). Caderno de Formação: Formação de professores. Avaliação educacional e escolar. 1. ed. São Paulo: Cultura Acadêmica: Universidade Estadual Paulista, Pró-Reitoria de Graduação v. 3, p. 92-110, 2013.

LUCKESI, C. C. Planejar, executar e avaliar. In: LUCKESI, C. C. Avaliação da aprendizagem escolar: estudos e proposições. 22. ed. São Paulo, SP, Brasil: Editora Cortez, p. 119-137, 2011.

PERRENOUD, P. Avaliação: da excelência à regularização das aprendizagens: entre duas lógicas. 1. ed. Porto Alegre, RS, Brasil: Editora Artmed, 1999.

SANTOS, A. B. Feiras de Ciência: Um incentivo para desenvolvimento da cultura científica. Revista Ciência em Extensão, v. 8, n. 2, p. 155-166, 2012.

VILLAS BOAS, B. M. F. Virando a escola do avesso por meio da avaliação. Campinas, SP, Brasil: Editora Papirus, 2008. 


\section{Como referenciar este artigo}

VICTORIO, Soraia da Silva; MIRANDA, Marcos Cesar Rodrigues; MARQUES, Rosebelly Nunes. A importância da avaliação formativa em feiras de ciências. Revista on line de Política e Gestão Educacional, Araraquara, v. 24, n. 1, p. 210-223, jan./abr., 2020. e-ISSN: 1519-9029. DOI: https://doi.org/10.22633/rpge.v24i1.13097

Submetido em: 07/10/2019

Revisões requeridas: 07/11/2019

Aprovado em: 15/12/2019

Publicado em: 06/01/2020 